\title{
THE EFFECT OF ILLUSTRATIONS ON CHILD PERCEPTION THROUGH DESIGNING INFORMATION DISPLAY SYSTEMS IN MUSEUMS OF ALL KINDS
}

\author{
Maha Darwish, ${ }^{1}$ Yumni Muhammad Fathallah Yaqout, ${ }^{2, *}$ \\ ${ }^{1}$ Department of Printed Design, Faculty of Fine Arts, Alexandria University, Egypt \\ ${ }^{2}$ Department of Graphic, College of Art and Design, Pharos University, Egypt
}

\begin{abstract}
Museums in most countries of the world are a platform for culture, science and art throughout the ages, and it is one of the educational and cultural means of communication that provides the visitor with an abundant experience of information, ideas, and scientific, artistic and aesthetic values. The Children's Museum is the laboratory in which a young child can satisfy his natural interests with arts, sciences, beauty and creativity. The International Museums Council has adopted the idea of children's museums. Therefore, we must pay attention to introducing the Egyptian child to his identity and the history of his ancestors. All these museums aim in the interest of children in the first place, as they help them to acquire facts, experiences and skills that are not achieved for them outside it through automatic learning and free play, and to achieve learning through exploration and provide an encourag ing environment. With the rapid technological advancements that have occurred in the field of computers, so-called virtual museums have emerged, which provide children with digital information in a way that suits their abilities and needs by exploring and presenting multiple sources of information, through which the child learns self-learning that will allow them to learn about other museums in all countries of the world. Without them having to go to it, because of the importance of realistic and virtual museums in the lives of our children and considering them a basic source for increasing their historical, geographical, artistic, literary and scientific information, and because it is the source of their formal and informal education, the study confirms the need to train specialists who have the ability to educational and artistic production of electronic or virtual museum content, and to create Cooperative frameworks in educational institutions through which museum gates can be opened to be windows to many museums. Keywords Illustrations, Child Perception, Designing, Information Display Systems In Museums Of All Kinds.
\end{abstract}

\section{Introduction:}

The museum can be defined as a permanent educational, cultural and entertainment institution that serves the community by collecting, preserving, displaying and maintaining the human and natural cultural and historical heritage, as it is the body that collects and maintains the heritage of humanity, preserves it and displays it in interesting and enjoyable ways.

The International Council of Museums (IcoM - The International Council of Museums) considers museums of all kinds the safe place in which the cultural, artistic, industrial, natural and historical heritage of mankind is preserved throughout the different historical eras.

Through visiting museums and viewing their collections, generations of all ages are able to learn about the cultural and civilizational legacy of the nations that preceded them, and learn about the pattern or patterns of real life that those ancient lived, the nature of the works that they practiced, the tools that they made and used in their daily lives, and the facilities and

\footnotetext{
* Corresponding author: info@pua.edu.eg
} 
buildings that they built And the arts that they practiced in the time periods in which they lived, as well as help in tracing the different stages of life and all that man left him during the different historical eras in various fields, and studying the material remnants that came to us in terms of antiques, pieces, archaeological tools, monuments, architectural and water installations, and ancient sites, to identify On the successive human-made civilizations in different regions of the world from thousands of years to the present age.

\section{Research problem:}

Lack of interest in establishing museums for children in Egypt, in addition to the lack of information in ways that suit the perceptions of children of all ages.

\section{Museology:}

A science independent of archeology, and it is one of the modern sciences that appeared in the modern era. Historical and archaeological discoveries were the direct cause of the emergence of museology.

The history of the emergence of museology specifically goes back to the end of the eleventh century and the beginning of the twelfth century AH, seventeenth - eighteenth century AD, and museum curators are considered to be the first founders of museum science, as they created methods and museum theories and introduced amendments to ancient museum works and theories.

The European Michael is considered the first scientist in museology, and the first book in this field, his book entitled The Science of Museums, which was published in Latin in the year 18 $\mathrm{CE}$, in which he dealt with the situation of museum curators in the world.

The science of museums has developed considerably in the present day, and this science has received great international attention since the end of the Second World War. In the middle of the twentieth century, the International Council of Museums "icom" was established and took New York City in the United States of America as its headquarters. After that, it established dozens of institutes and institutions concerned with the study and development of museum science and the rehabilitation and training of museum workers. Museum science has become one of the important sciences that are taught in international universities, colleges and institutes of archeology, arts and tourism in many countries of the world that have been keen and keen to build and develop museums, pay attention to their contents and use the best museum display methods, as the museum is one of the most important tourist attractions.

\section{Mission and objectives of the museum:}

Visitors come to museums to see their archaeological and artistic contents. The museum's function is mainly focused on preserving, maintaining and displaying models from the 
remnants of ancient civilizations. Museums have multiple functions and carry an educational, educational, cultural, tourism, artistic, scientific, social, ethical, patriotic and national mission. The various museums work to achieve many important goals for the sake of serving the individual and society, as they undertake the preservation of the historical and cultural heritage by collecting scientific and historical information, acquiring pieces, antiquities and documents in order to record, photograph and preserve them, restore what needs restoration, and display it in a manner that enters Have fun on your visitors.

Museums also work to support and encourage research, excavation and systematic scientific exploration of antiquities through the assistance of local and international scientists, specialists, and experts, and contribute to popularizing culture, spreading knowledge, and revitalizing the artistic and scientific movement in society.

Museums are one of the means of developing the aesthetic sense and artistic taste of the individual and society. Museums develop freedom of thought and accuracy of observation among their visitors. It provides educational services and helps to consolidate knowledge of the history and civilizational, cultural and artistic roots of nations and peoples, and the interpretation of the present and the past for individuals and societies alike.

\section{Changes in display in museums:}

Museums are no longer just silent exhibition spaces, but there are other trends in information display systems within contemporary museums that are evolving in succession, reflecting technological development. And there are increasing trends in this sector to achieve integration in the presentation of new methodologies and strategies designed to enhance visitor participation. Cultural institutions are facing the future in new ways, addressing the challenges of preserving heritage as well as preserving the relevance of cultural and technological development. Therefore, cultural institutions are now interested in strengthening the systems of interaction and participation with the recipient in the communication process and the systems for presenting and displaying information, which attract Visitors of all ages.

\section{Technological development in museum design:}

Museums were interested in their design by focusing on the use of technology in the nineteenth century, when exhibition design was developed and interactive display systems were incorporated, enabling visitors to press a button to make an impact or control the information content that is displayed.

Science museums and science centers in particular played an important role in challenging the traditional presentations of exhibitions.

Making static objects active to attract museum visitors, especially young children. Instead of 
displaying a static object, it becomes more important to show ideas, information, and how users participate. Questacon, the National Science and Technology Center is based in Canberra.

\section{Display technology in the interactive museum:}

There are many ways that museums and cultural places can use interactive technology to make themselves more futuristic, but they can be grouped into six types of technology. When it comes to creating communication with an audience, we must turn to interactive technology, which has proven effective in attracting visitors of all ages to cultural institutions around the world. For example, when museums faced a decline in visitor numbers, museum executives at MOMA decided to incorporate the prevailing culture of interaction that we now live in into the museum experience because interactive museums rely on creating a dual interaction between visitors and views, putting the visitor experience into Center stage.

\section{Museum apps:}

Mobile applications have become an integral part of our daily life, along with entertainment applications. In light of this, it is not surprising that leading cultural institutions such as the Tate Modern and the National Portrait Gallery are developing their own apps to make artworks more accessible and enhance the feeling of exploration in every visitor. Using these apps, visitors can create pools, share their discoveries through social networks and display their favorite works in their homes using augmented reality technology.

\section{Interactive audio guides:}

The Louvre Museum provided a good example of how to give traditional museums a tool that allows more interactive communication with visitors, such as an audio guide that is given to the visitor who can explore through interactive display technology. The museum offers audio guides on the Nintendo DS, which enables a dual screen to display interactive maps. In addition, the museum offers GPS technology, which facilitates road search, and displays visual content - including 3D images - to complement the audio experience.

\section{Video walls / Interactive Walls:}

They were used with success to challenge the passive role of museum-goers and turn it into a practical experience. At the Cleveland Museum of Art, video walls display a selection of the museum's galleries. The museum display is based on exploration and a live interactive experience between each visitor, where visitors can connect their portable devices to the wall via Bluetooth, download and save favorite files, and watch tours and groups

Exhibits made by previous visitors.

\section{Interactive floor projection system:}


The display system through interactive floors provides fun, exciting, and engaging educational experiences for children. Where the images respond to the movements and signals made by the child, allowing the child to easily interact and participate in stimulating audio-visual experiences.

The interactive display helps promote inclusive practices in education by engaging children of all ages and abilities.

\section{Augmented \& virtual reality:}

Augmented reality and virtual reality are used in international museums to help visitors interact with different exhibits through the use of their mobile phones. AR apps at the Detroit Institute of Arts engage visitors in artwork by solving puzzles or encouraging visitors to find specific details in the art paintings displayed.

\section{Self - service technology:}

Like the kiosks scattered throughout the many museums, they allow visitors an opportunity to create their own experience while they are at the venue. Self - service kiosks can be used for various purposes, such as providing information to find routes, visitors can also give notes, sign up for museum memberships, donate and print entry tickets. The Penn State Museum is a good example of the interactive and faithful use of touch screens with digital signage helping visitors create a personalized experience.

\section{Hologram technology:}

Due to its three-dimensional nature, this interactive technology helps to effectively integrate visitors with the exhibits and can be used in different types of museums such as future proof museums by introducing the visitor into an experimental virtual environment. They can bring them to life again through digital animations and thus become digital storytelling tools that help create memorable and rewarding experiences.

Museums and cultural places play a critical role in preserving a community's heritage and sense of identity. At the same time, they function as educational spaces that allow visitors to explore different aspects of history and society. But because interactive technology has revolutionized the way we think about many aspects of our lives.

\section{Communication with visitors:}

Allowing visitors, especially the very young, to explore and discover things in new ways has now become a major focus of many institutions. We are witnessing the integration of interactive technologies that integrate with all the senses. The use of digital technologies has a major role in communication processes and the integration of visitors with the scientific material provided by museums, which helps to facilitate and accelerate cultural interpretation 
and may attract new cultural audiences. The recent shifts in museum design reflect an attempt by these institutions to move away from imposing a single perspective on display systems. Contemporary museums have shown a real desire to rethink the roles of history, culture and learning, and to explore how technology changes the relationship between audiences and the information they provide.

\section{References:}

1- Mai Abdel Hamid, Youmna Fathallah, The Role of Interactive Infographics in the Interior Design of Contemporary Museums, Journal of Islamic Arts and Architecture.

2- Shaltout. Infographic from planning to production. King Fahd National Library 2017, Riyadh - Kingdom of Saudi Arabia

3- Janson Lankow, Josh Richie, Ross Crooks, INFOGRAPHICS the power of visual story telling, Published by John Wiley, 2012, Canada .

4- Andrew loomis, Creative illustration, The Viking Press, New York, 1947.

5- Jenn, O'Grady.k, the information design handbook, RotoVision SA, Switzerland, 2008.

6- http://theconversation.com/museum-or-not-the-changing-face-of-curated-science-tech-artandculture-95507

7- https://borderless.teamlab.art/ew/way-of-the-sea-colors flying/

8- https://vimeo.com/199311490

9- https://www.lamasatech.com/blog/future-proof-museumsinteractive-technology/

10- https://www.mikeayresdesign.co.uk/explore-app/omi-vista-interactive-floors

11- https://www.lamasatech.com/blog/future-proof-museums-interactive-technology/

12- https://childrensmuseumofphoenix.org/exhibits-and-experiences/

13- http://have-kids-will-travel.com/index.php/2017/04/28/nashville-tennessee-adventuresciencecenter/

14- http://187educationtecnology.blogspot.com.eg/2014/01/blog-post.html

15- https://www.3dvisworld.com/features/feature-articles/2660-the-value-of-3d-to-educationandlearning.htmlhttp://have-kids-will-travel.com/index.php/2017/04/28/nashville-tennesseeadventurescience-center/

16- https://www.fieldmuseum.org/exhibitions/evolving-planet

17- http://www.kossmanndejong.nl/en/project/micropia-artis/

18- http://museumzero.blogspot.com.eg/2013/06/museums-in-digital-age.html

19- https://visual.ly/m/what-are-interactive-infographics-2/

20- https://www.snapapp.com/platform/interactive-content-types/interactive-infographics

21- http://www.potiondesign.com/project/future-energy/ 
22- http://www.sdhwork.com/Patricia-Phillip-Frost-Museum

23- https://Irbizarrebazaar.wordpress.com/2012/03/27/1679/

24- www.fredericevl.de

25- www.hyposurface.org

26- Https://Gnsi.Org/Science-Illustration Careers-Ed 2015

27- Http://Www.Biologyforlife.Com Lab-Drawings Html

28- Https://Lauragarrison. Wordpress.com/2011/04/10/Broedel-Illustration/

29- http://www.drawingincolor.com/plant-id-pages-gallery-full/

30- https://www.formula-d.co.za/projects/virtual-everglades-tunnel/

31- http://visualoop.com/alfredo peralta

32- http://visualoop.com/alfredo peralta

33- http://visualoop.com/infographics/cheetah

34- https://formula-d.com/projects/interactive-frog-touch-wall/

35- http://paulweston.info/Geological-Illustration June, 2017

36- https://www.discoverykidslv.org/exhibits/young-at-art/

37- https://www.childrensmuseum.org/exhibits/treasures

38- http://ilp.unrwa.org/

$39-$

https://mawdoo3.comA7\%D99684\%D8\%AA\%D99681\%\%A7\%D8\%B9\%D9\%84\%D9\%8A 40- Hoda Gad El Rab Abdo MDKOUR, STUDY OF INTERACTIVE LEARNING SPREADS WITHIN EDUCATIONAL ESTABLISHMENTS, International Journal of Education and Learning Research, Vol. 2, No. 1, 2019, pp. 1-4

Received: September 15, 2019

Accepted: November 20, 2019 